This item was submitted to Loughborough's Research Repository by the author.

Items in Figshare are protected by copyright, with all rights reserved, unless otherwise indicated.

\title{
Fatal and serious collisions involving pedal cyclists and trucks in London between 2007 and 2011
}

PLEASE CITE THE PUBLISHED VERSION

http://dx.doi.org/10.1080/15389588.2017.1291938

\section{PUBLISHER}

(c) Taylor \& Francis

\section{VERSION}

AM (Accepted Manuscript)

\section{PUBLISHER STATEMENT}

This work is made available according to the conditions of the Creative Commons Attribution-NonCommercialNoDerivatives 4.0 International (CC BY-NC-ND 4.0) licence. Full details of this licence are available at: https://creativecommons.org/licenses/by-nc-nd/4.0/

\section{LICENCE}

CC BY-NC-ND 4.0

\section{REPOSITORY RECORD}

Talbot, Rachel, Steven Reed, Nicola Christie, Jo Barnes, and Pete Thomas. 2017. "Fatal and Serious Collisions Involving Pedal Cyclists and Trucks in London Between 2007 and 2011”. Loughborough University. https://hdl.handle.net/2134/24192. 
Fatal and serious collisions involving pedal cyclists and trucks in London between 2007 and 2011

Rachel Talbot ${ }^{\mathrm{a}^{*}}$, Steve Reed $^{\mathrm{a}}$, Nicola Christie $^{\mathrm{b}}$, Jo Barnes $^{\mathrm{a}}$, Pete Thomas $^{\mathrm{a}}$

${ }^{a}$ Loughborough University, Ashby Road, Loughborough, LE11 3TU, UK

${ }^{\mathrm{b}}$ University College London, Gower Street, London, WC1E 6BT, UK

*corresponding author - email r.k.talbot@lboro.ac.uk

\begin{abstract}
Objective: Increased numbers of people riding pedal cycles has led to a greater focus on pedal cycle safety. The aim of this paper is to explore factors that are associated with fatal and a small number of serious injury pedal cyclist crashes involving trucks that occurred in London between 2007 and 2011.

Methods: Data were collected from police collision files for 53 crashes, 27 of which involved a truck $(\geq 3.5$ tonnes) and a pedal cycle. A systematic case review approach was used to identify the infrastructure, vehicle road user and management factors that contributed to these crashes and injuries and how these factors interacted. Results: Trucks turning left conflicting with pedal cyclists traveling straight ahead was a common crash scenario. Key contributory factors identified included the pedal cyclists not being visible to the truck drivers, road narrowing and inappropriate positioning of pedal cyclists.

Conclusions: Crashes involving trucks and pedal cyclists are complex events that are caused by multiple interacting factors therefore multiple measures are required to prevent them from occurring.
\end{abstract}

\title{
KEY WORDS
}

Cyclist; Trucks; Crash; Contributory Factors; Road Safety; Fatality

\section{INTRODUCTION}

In 2014, 113 cyclists were reported to have been killed as a result of a road traffic collision in Great Britain (Department for Transport, 2014). Despite a long term reduction in fatalities of all road users in Great Britain, this downward trend has not been observed for pedal cyclists. Between 2009 and 2013, the number of pedal cycle fatalities fluctuated between 100 and 120 with some evidence of a slight upwards trend (Department for Transport 2013). In addition the numbers of seriously injured pedal cyclists show a long term increase with 2,174 being recorded in 2004 and 3,401 in 2014 (Department for Transport, 2014). At the same time the numbers of people cycling has increased. Census data has shown that there have been increases in the numbers of people cycling to work in many major English cities between 2001 and 2011 with over an $80 \%$ increase in Brighton, Bristol, Manchester, Newcastle and Sheffield with a particularly high increase of 144\% in Inner London (43,494 and 106,219 people respectively, Office for National Statistics 2014). This has led to a greater 
focus on cycle safety in the UK - especially in areas such as London where there has been particular efforts to increase the numbers of people who regularly cycle (e.g. Transport for London 2013).

In addition there appears to be an overrepresentation of truck involved fatal pedal cyclist crashes. Trucks make up 5\% of the traffic in Great Britain (GB) and 2\% of pedal cyclist casualties but in contrast, $23 \%$ of fatal crashes involve a truck (Department for Transport 2013). Keigan et al. (2009) reported that in London this figure is even higher with $39 \%$ of fatal pedal cycle crashes involving a truck ( $\geq 7.5$ tonnes). To explore this issue further, this paper focuses on the factors associated with fatal and a small number of serious injury pedal cyclist crashes involving trucks that occurred in London between 2007 and 2011.

\section{Key Literature}

Factors associated with cyclist crashes have been studied in a number of countries, most commonly using national statistics data derived from police reported crashes. Stone and Broughton (2003) studied 30,000 records of fatal and serious injury pedal cycle collisions occurring between 1990 and 1999 which were recorded in the GB national road traffic crash statistics, known as STATS19. They found that three-quarters of these crashes occurred on $30 \mathrm{mph}$ roads with $70 \%$ occurring at or within 20 metres of a junction and that the fatality rate rose with the speed limit and age of cyclist. Kaplan et al (2014) analysed national records of police reported road traffic collisions in Denmark for the years 2007-2011. They found that the majority (75\%) of crashes occurred in a $50 \mathrm{~km} / \mathrm{h}$ zone and half the crashes occurred when the cyclist was travelling straight on and the driver was turning. Cycle verses truck collisions accounted for $3.4 \%$ of the observed crashes, were associated with the most severe injuries, and increased the probability of severe injury by $71 \%$ and fatal injury by $1145 \%$. Ackery (2012) found that in the USA, larger motor vehicles were particularly common in bicyclist deaths compared to the control [non-bicycle] deaths, especially freight trucks.

Keigan et al. (2009) studied detailed police collision files for 92 fatal pedal cycle crashes that occurred in London between 2001 and 2006. Thirty-seven of these crashes (40\%) involved a heavy goods vehicle $(\geq 3.5$ tonnes) and the most common crash scenario (23 crashes) involved a heavy goods vehicle (HGV) or bus/coach turning or changing lanes to the left and striking the pedal cyclist . Blind spot crashes - where a pedal cyclist has been travelling straight on and being in collision with a truck turning right (equivalent to UK left turn crashes) - have been considered to be an issue for several years in the Netherlands (Schoon et al 2008) and Germany (Niewoehner and Berg, 2005). This was found to be a particular issue when the driver was setting off from a stationary position e.g. at a signal controlled junction. Old cab designs (pre 2007), failure of truck drivers to use or adjust their right hand mirrors correctly and pedal cyclists being unaware of truck blind spots were cited as key contributory factors to such crashes (Schoon et al 2008). In a German in-depth study examining 45 pedal cyclist and pedestrian collisions with a truck where the truck was turning right, Niewoehner and Berg (2005) found that in over half of the crashes initial contact was made with the pedal cyclist or pedestrian with the front right hand corner of the truck. The authors cited issues with direct and indirect view to the right and front of the truck to be a specific issue. Johannsen and Otte (2015) also used in-depth data and methodologies to examine truck and pedal cyclist crashes and concluded that right turn (equivalent to left turn in the UK) were a particular issue with direct and indirect vision issues playing a part. 
Few studies (Keigan et al, 2009, Niewoehnr and Berg, 2005 and Johannsen and Otte, 2015) have been conducted using in depth data and methodologies to examine pedal cycle and truck crashes. Such studies tend to have a relatively small sample size but give a greater insight into the manoeuvres and sight issues associated with truck and pedal cycle crashes than those utilising national statistics and therefore add valuable knowledge about such crashes. This paper aims to add to the relatively small body of knowledge in this area and thus provide greater insight into the causes of pedal cycle and truck crashes.

\section{Theoretical Approach}

Theoretical approaches to the analysis of road collisions have their roots in the study of workplace safety. Haddon (1968) drew on workplace safety approaches to develop what is now known as the Haddon Matrix to help identify the role of the road user, vehicle and environment in collision causation and crash outcomes. A limitation of this approach is that whilst it decomposes the key elements of the events in terms of characteristics of pre, during and post-crash phases it does not look at the complex interplay between them. Collision analysis was further developed by Reason (2000) who argued that whilst people make errors there are often no consequences because there are a variety of barriers in place. However, if these barriers have weaknesses that occur at the same time and place when an unsafe act occurs this can provide a "trajectory of accident opportunity" and a collision can occur. The model is useful because it places crashes in the context of a sociotechnical system and helps to show the importance of the management and regulation of that system i.e. by creating defensive layers. However, the model has been criticised for being over simplistic and not providing a detailed protocol about how to identify complex interplay between causal factors. In particular, it does not show how to identify 'holes' in the system, why they are there in the first place, and how and why they change in size and over time in a real world setting (Shappell \& Wiegmann 2000; Wiegmann and Shappell 2003).

The study reported here combined elements of the approaches proposed by Haddon (examining the pre, crash and post-crash stages) and Reason (examination of road transport as a system with the potential for management/regularity errors in addition to road, vehicle and human) but also introduced a more detailed systematic approach to collision analysis involving in depth case review by a multidisciplinary expert panel. This approach shares similarities to approaches used to investigate the deaths of children related to neglect or abuse (HM Government, 2015). The aims of such case reviews are to make a robust, systematic analysis of what happened and why and improve preventive measures. The case reviews are generally conducted by an expert panel which, in the case of child safeguarding, comprises service providers with a role in child protection and health such as social services, police, health services etc. This approach has recently been used for road deaths among young drivers (Pilkington et al, 2014) and piloted for young people's deaths in motor vehicles as part of the National Child Death Review (CDR) programme (Public Health Wales, 2013). However, the focus of these reviews has been on the casualty only and not on the role of the collision partner.

This paper will describe the results of a systematic case review approach to the analysis of collisions between pedal cyclists and trucks which have led to the death or serious injury of a pedal cyclist. This analysis has been conducted to identify both 'unsafe acts' and 'holes' in the system through the multidisciplinary lens of an expert panel. To this end, it can be said the crashes are failures in a road traffic system made up of four components: 
- Environment: This includes aspects such as infrastructure and weather conditions.

- Vehicle: All vehicles (including bicycles), their design and safety systems.

- Road User: The human behaviour element in the system - drivers, pedestrians, pedal cyclists, motorcycle riders etc.

- Management: These are the indirect influences of the system including legislation, policy and procedures e.g. licensing, congestion charging, fleet management, which in turn influences factors such as who is on the roads and when.

\section{METHODOLOGY}

\section{Primary Data Source}

The primary source for data collection was Metropolitan Police (London) collision investigation files. These files contained detailed information about the fatal and serious pedal cycle collisions and the circumstances surrounding them. Key documents were as follows:

- Collision investigation report

- Scene and vehicle photographs

- Driver interview transcripts

- Witness statements

- $\quad$ Post-mortem reports

All police files were accessed at a secure London police station and data collection was governed by a confidentiality agreement between the Metropolitan Police, the researchers and the funder (Transport for London)

\section{Identification of Key Variables}

The first step was to identify a list of variables that would describe the collision in detail and within the context of the road traffic system (see Introduction, Theoretical Approach). The following elements were focused upon:

- Environmental factors

- Involved vehicles,

- $\quad$ Road Users

- Management, including factors that affect the whole system

- Difference phases of the crash: pre-crash, the crash itself and post-crash, including injuries

To ensure key variables were included, a review of the variables chosen by other data collection studies using a systems approach was undertaken. These studies were the SafetyNet Fatal Accident and Accident Causation Databases (Reed and Morris, 2008), the DREAM manual (Wallén-Warner et al. 2008) and the European Commission supported, Road Safety Data, Collection, Transfer and Analysis (DaCoTA) project's Pan-European In-Depth Accident Investigation Online Manual (DaCoTA, 2012). 
A stakeholder workshop was then held with members of the Transport for London Cycle Safety Working Group to establish the key questions relating to cyclists in London. The variable list was reviewed and a small number of variables were added to make sure that the data collected could address these questions.

\section{Database and Supplementary Documents}

A simple database was created to record data collected from the police files. This consisted of a mixture of variables with a choice of pre-defined values and free text fields. For a full variable and value list, see Appendix Tables A3-A12. Additional materials were also collected to supplement the database variables. These supplementary documents were as follows (data source stated in brackets):

- $\quad$ Scene plans and photographs (police files)

- $\quad$ CCTV images (police files)

- Vehicle damage diagram (derived from police files)

- $\quad$ Crash scenario diagram (derived from police files)

- $\quad$ Injury coding variables including Abbreviated Injury Scale (AIS) values (AAAM, 2005 - 2008 update) (derived from police files)

- Number and type of crash at location during previous three years (Extracted from STATS19 data, provided by Transport for London)

\section{Data Collection and Quality Control}

A pilot was undertaken to test the data collection procedures. Data from ten crashes involving a range of vehicle types were collected. As a result of this pilot, some minor changes were made to the database structure and a glossary was developed to provide the data collectors with additional information about the variables and coding conventions that were developed during the pilot.

Data were collected by a team of four researchers. Three of these were responsible for recording the crash data in the database and collecting or creating the supplementary documents and all had relevant previous experience. The forth was a specialist in AIS injury coding (Certified trainer of AIS 2005 and Certified Abbreviated Injury Scaling Specialist (CAISS)) and was responsible for recording the injury data.

Both following the pilot and the completion of data collection, the full data set - both the database and supplementary documents - were reviewed to check for completeness and data entry or coding errors.

\section{Data Analysis}

Due to the relatively small sample size of 27 crashes, it was not thought appropriate to perform statistical tests. Instead the database values were used to describe the characteristics of the crashes using descriptive statistics. Injury data was collected from police files (Post mortems, medical witness statements) and Abbreviated Injury Scale (AIS) values (Maximum AIS, ISS) were calculated according to standard methodologies (AIS 2005 2008 update; AAAM, 2008). 
Further analyses were undertaken to identify 'crash scenarios', 'initial point of contact between cyclist and truck' and 'relative movement of cyclist and trucks', as reported in the results section. A researcher undertook a context style analysis of key 'free text' database variables ('Accident Description', 'Driving manoeuvre prior to crash', 'Bicycle/vehicle interaction comment', 'Events (pre, during and post-crash) description', 'Road narrowing description') and the supplementary documents 'scene plans and photos', 'CCTV images' and 'scenario diagrams' to group the crashes according to the most common characteristics according to their movements and interactions pre, during and after the crash occurred. This resulted in the creation of two crash scenario categories, which were further divided into subcategories. Additional database variables (Type of collision, which lane truck/cyclist was travelling in, Junction type/control, Advanced stop line present) were also used to assist in this process. A similar process, in terms of the context analysis and data sources, was used to identify the initial point of contact between the cyclist and truck and their relative movement. Where this process differed is described below.

To identify the initial point of contact between cyclist and truck, the point of interest was only when first contact was made between the pedal cyclist and truck - not where the pedal cyclist had been riding prior to that point or where they were eventually run over. The truck was divided into eight zones - four on the front cab area and four to the nearside (left) of the truck. The zones were not equal in size and attempted to distinguish between a contact point with the front, the front corner and the left side of the cab as well as those other key sites to the left side of a truck - the fuel tank area and the trailer where side guards may or may not be fitted. For crashes occurring on the front left corner of the cab, a judgment had to be made about whether it was more a 'front' collision or a 'side' collision.

For the relative movement of cyclist and trucks analysis, the categories to which the crashes were assigned were pre-defined according to all possible overtake or undertake manoeuvres and whether the truck and/or pedal cyclist was moving. The timeframe of interest was the period immediately prior to the crash's occurrence but before any contact was made between the truck and pedal cyclist. Of all the analyses, this was the most complex due to the dynamic nature of this type of cash and the one most reliant on the judgement of the researcher. To try and minimise errors, the exercise was repeated on two separate occasions and category assignment was checked by another researcher.

Identification of Contributory factors: a case review approach A case review approach was undertaken to identify which aspects relating to the crash contributed to its occurrence. The detailed information recorded in the database and supplementary documents was reviewed for each crash by a panel of researchers. The following questions were asked about each crash:

- What happened?

- Why did it happen?

- Which factors contributed to the crash's occurrence?

These contributory factors were recorded under the following headings:

- Infrastructure (including environmental factors)

- Vehicle 
- $\quad$ Road User (subdivided, pedal cyclist and other road user)

- Management

This enabled a discussion to take place about the potential countermeasures that could have been in place that would have prevented the collision. Each contributory factor was assigned a countermeasure where possible. This bottom up approach of identifying actual contributory factors from the evidence gathered for each collision enabled an in-depth understanding of the crash within the context of its occurrence to be established (cf. Hennink et al 2011, p10.)

This methodological process was repeated for each collision with at least four researchers with expertise in human factors, vehicles, crash investigation and injuries. Once this approach to the case review was established the remaining crashes were reviewed by at least two researchers.

The main factors found to contribute to crashes, as identified during the case reviews, are reported in the results section.

\section{RESULTS}

Seventy-nine fatal and serious crashes occurring in London were investigated by the Metropolitan Police Force between 2007 and 2011, of which, 53 were available for analysis - see Figure 1 for description of the sample.

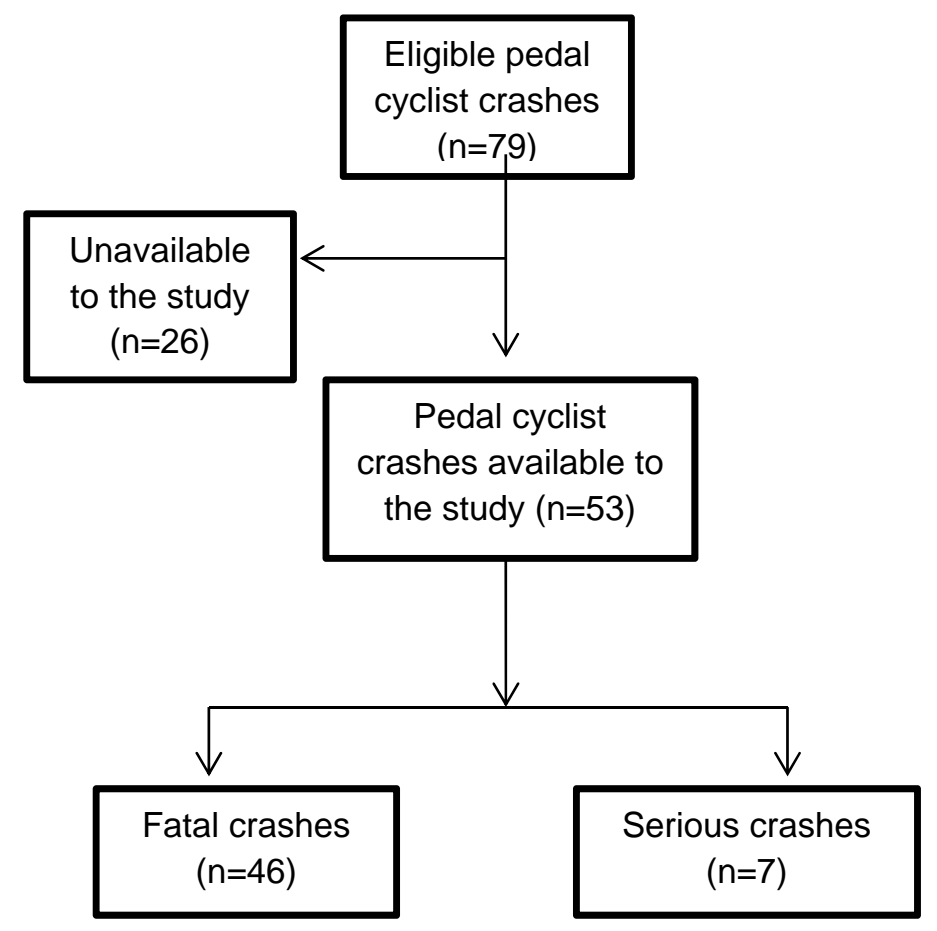

Figure 1: Description of sample

It was not possible to include 26 of the 79 crashes in the study. Seven files (five involving a truck) were unobtainable because of ongoing judiciary processes at the time of data collection in 2013. It was not possible to identify the location of the file for 11 crashes (six involving a truck) and a further six (no truck involvement) 
were excluded from the study as they were incomplete and did not contain sufficient information to analyse. The remaining two were considered out of scope as the fatalities were pedestrians not pedal cyclists. There was an over-representation of excluded crashes from the end of the sample period (13 from 2011) including all the files linked with the judiciary process. The remaining files were spread relatively evenly across the sample years 2007-2010. 12 of the excluded crashes involved a car, 11 a truck, two a pedestrian and one a van.

In the following results and analysis, the fatal and serious crashes have been grouped together as the characteristics of the serious crashes, in terms of crash causation, were very similar to those of the fatal crashes.

Table 1 shows the primary collision partner for the 53 fatal and serious crashes examined. The primary collision partner is defined as the vehicle that was involved in the initial interaction with the pedal cyclist. If the initial interaction was between the pedal cyclist and another cyclist or a stationary object (including a parked unattended car) the crash is counted as a 'pedal cycle' crash - even if the cyclist was subsequently in collision with another type of vehicle. A truck was the collision partner for just over half of the crashes with cars making up the second largest collision partner group. The pedal cycle group includes two crashes where the initial collision occurred with another cyclist and the remaining three were caused by the cyclists losing control or hitting a stationary object.

Table 1: Number of crashes by primary collision partner

\begin{tabular}{|l|c|c|}
\hline $\begin{array}{c}\text { Crash } \\
\text { Participant }\end{array}$ & $\begin{array}{c}\text { Number } \\
\text { of } \\
\text { Crashes }\end{array}$ & $\begin{array}{c}\text { \% of } \\
\text { Crashes }\end{array}$ \\
\hline Car & 15 & 28 \\
\hline Van & 2 & 4 \\
\hline Bus/Coach & 3 & 6 \\
\hline Truck $\geq 3.5 \mathrm{t}$ & 27 & 51 \\
\hline Motorcycle & 1 & 2 \\
\hline Pedal Cycle & 5 & 9 \\
\hline Total & 53 & 100 \\
\hline
\end{tabular}

\section{Crashes Involving Trucks $\geq 3.5$ Tonnes $(\mathrm{n}=27)$}

Twenty-seven crashes in the sample involved a truck $\geq 3.5$ tonnes as the primary collision partner. Twentyfour of these crashes were fatal and the remaining three resulted in the pedal cyclist sustaining serious injuries. Twenty-six of the crashes occurred on a week day with the remaining crash occurring on a Saturday morning. Over half $(16 / 27,59 \%)$ occurred before 10:00 with nine occurring between 08:00 and 8:59. Twenty-two crashes occurred in daylight and the remaining five occurred in darkness or partial light conditions. The majority of crashes occurred in fine weather (25/27) with only two crashes occurring while it was raining. All the crashes occurred on roads with a speed limit of 30 miles per hour, 19 were on two-way roads, six on oneway and two occurred on dual carriageways. Twenty-four of the crashes occurred on or within $20 \mathrm{~m}$ of a 
junction, of which 22 were signalised. Crossroads was the most common junction type with 14 crashes and three crashes occurred at a roundabout.

The majority of trucks in the sample had rigid bodies with only three being articulated and one being a tractor unit without a trailer (Error! Reference source not found.2). All three articulated trucks were curtain style. The most common rigid body trucks types were tipper (11), flat / drop side (5) and box (4).

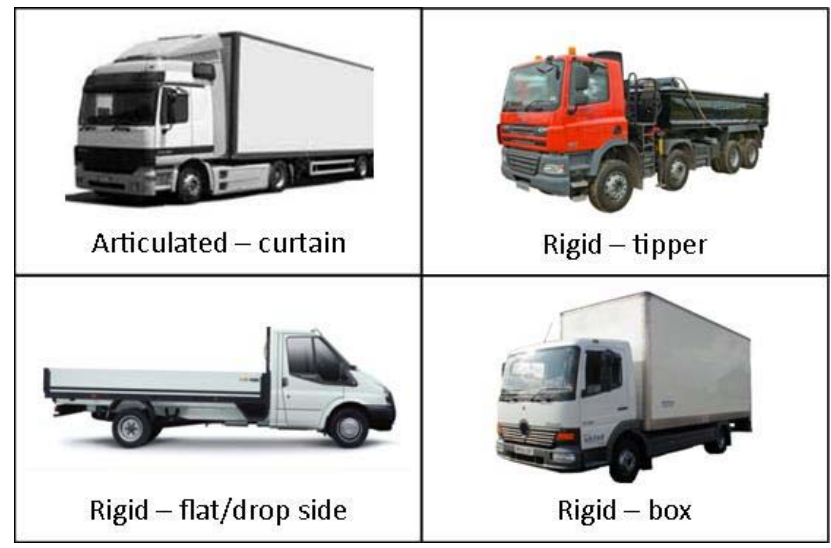

Figure 2: Truck body styles

Out of the 27 crashes involving a truck, 25 were in the weight category $>7.5 \mathrm{t}$ with the remaining two trucks in the 3.5-7.5t category. 13 trucks were fitted with a Class V close proximity mirror, providing vision of the nearside (left) cab area, and a Class VI front mirror, providing vision of the ground in front of the. Ten trucks had a Class V but not a Class VI, one truck had neither fitted and the fitting of mirrors for three trucks was unknown. It was not possible from the data available to ascertain whether these mirrors were correctly adjusted to afford optimum view. Side guards were fitted to 11 trucks, 13 did not have side guards and for 3 trucks it was unknown whether or not they had side guards. Five of the trucks had Class V, Class VI and side guards fitted.

The cyclists had an age range of 16-67 with a mean age of 32 years old. Seventeen cyclists (63\%) were female. The truck drivers had an age range of 25-64 with a mean of 46 years old. All the truck drivers were male.

\section{Injuries}

Twenty five cyclists had known injuries that could be coded to the AIS 2005 (2008 update) standard (AAAM, 2008). The absence of detailed injury descriptions in the case files meant that some injuries were coded conservatively and possibly do not reflect the true severity of some of the injuries sustained. Despite this the use of the Abbreviated Injury Scale identifies the location and severity of the injuries sustained allowing for indepth case studies to be conducted using standard injury terminology.

Injuries were categorised according to the Maximum AIS by body region and ISS was also calculated. The ISS ranged between 9 and 75 with the mean ISS 40.6, median 41. MAIS ranged between 3 and 6 denoting the highest severity injury for each cyclist, notably there were a number of cyclists with multiple injuries of the same severity. Where this occurred the body region selected to represent the individual was ranked accordingly with Head as the priority, Thorax, Abdomen and Extremities. For Males with fatal injuries, the MAIS was 
attributed to the 'Head or Neck' and 'Thorax' body regions and for females this was distributed across the four body regions 'Head or Neck', 'Thorax', 'Abdomen' and 'Extremities'. Only three cyclists did not receive fatal injuries and were all female with the predominant injuries sustained to the pelvis (Extremities). For MAIS by body region figures see Table A1 (see Appendix).

Overall the body regions sustaining the most serious injuries were the thorax and head or neck and those with maximal AIS 6 injuries tended to be crush injuries sustained by being run over by the truck. The MAIS extremity injuries were pelvic fractures and again tended to be serious fractures sustained from being run over from the truck. Other injuries of note although not represented by the MAIS table were external injuries for example degloving (where an extensive amount of skin is torn off underlying tissue) to extremities which although not life threatening are difficult to heal.

\section{Crash Scenarios}

The crashes involving a truck were typically low speed collisions. In 18 crashes, the truck was turning left (In the UK drivers drive on the left) and in 17 of these it was believed that the cyclist intended to travel straight ahead. In the remaining nine crashes the cyclist and truck were travelling in the same direction and lane and both performing the same turn manoeuvre i.e. left, right or straight on. A summary of the crash scenarios and their sub-categories (discussed below) can be found in Table A2 (see Appendix).

Left turn group detail $(\mathbf{n}=\mathbf{1 8})$ Within the left turning truck group, two scenarios were common and characterised 11 out of the 18 crashes. In the first scenario (1a), the crash occurred whilst negotiating a signalised $(n=6)$ or give way $(n=1)$ junction, when the truck and cyclist were travelling alongside each other or the truck was very close to the rear of the cyclist, either as a result of an undertake manoeuvre by the cyclist $(n=5)$ or an overtake manoeuvre by the truck $(n=2)$.

In the second scenario (1b), the crash occurred as both the cyclist and the truck set off in response to a green light, having previously been stationary, with the cyclist in an Advanced Stop Line (ASL) area. ASLs are used at some signalised junctions in the UK to demarcate an area where cyclists can wait at a red light ahead of the motorised traffic. Out of these four crashes, three involved the cyclist undertaking the truck to gain access to the ASL while the traffic signal was set to red and in the remaining crash the truck had entered the ASL resulting in a number of cyclists being positioned on its nearside.

In a third scenario (1c) the truck was travelling through a left turn only signalised junction with an integrated bus/taxi and cycle lane accessed by travelling straight ahead. In both crashes the truck was travelling in lane two while the cyclist was travelling in lane one with the definite intention of traveling straight ahead in one crash and possibly attempting this manoeuvre in the other.

The remaining crashes in the left turning truck group, were characterised by the cyclist using the pavement to undertake stationary vehicles and re-entering the road to the nearside of the truck (1d); and the truck failing to give way to the cyclist (1e).

Same direction group detail $(\mathbf{n = 9})$ Nine crashes occurred when cyclists and trucks were travelling in the same direction, in the same lane. Seven of these crashes were characterised by the cyclist 'running out of space' 
(2a) meaning that the available lane width narrowed forcing the cyclist and truck into closer proximity when they were traveling alongside each other.

Five of these crashes occurred at junctions - both the truck and the cyclist were turning left in two crashes, turning right in one and travelling straight on in two. The sixth occurred as the road narrowed on the approach to a junction and the seventh crash occurred in close proximity to a pelican crossing on a build-out. In three of the 'running out of space' crashes, the truck was just starting to move in response to a green light and the cyclist was probably moving. In one crash both the truck and the cyclist were setting off from stationary and for three both the cyclist and the truck were moving when the crash occurred.

The remaining two crashes in the same direction group, were characterised by the truck running into a cyclist who had entered the space immediately in front of the truck while the truck was stationary (2b). In the first crash the cyclist had entered an ASL by overtaking a truck that was stationary at a signalised junction. In the second the cyclist undertook and pulled in front of a truck that was stationary in a line of traffic on the approach to a signalised junction.

\section{Initial point of contact between cyclist and truck}

Error! Reference source not found. shows the initial point of contact between the truck and cyclist. The truck did not necessarily run over the cyclist at this point - in some crashes the cyclist was hit by the cab area of the truck, knocked to the ground and then run over by the rear wheels. The initial contact points cluster around the nearside (left) front corner of the truck. Out of the 15 crashes where contact was made to the front of the truck (F1-4), six trucks were not fitted with a Class VI close proximity mirror, six were equipped and it was unknown for a further three. For the two zones (S1-2) served by the Class V close proximity mirror, trucks were fitted with this mirror for all eight crashes. Where the initial contact point was zone S4, neither of the two trucks had a side guard fitted.

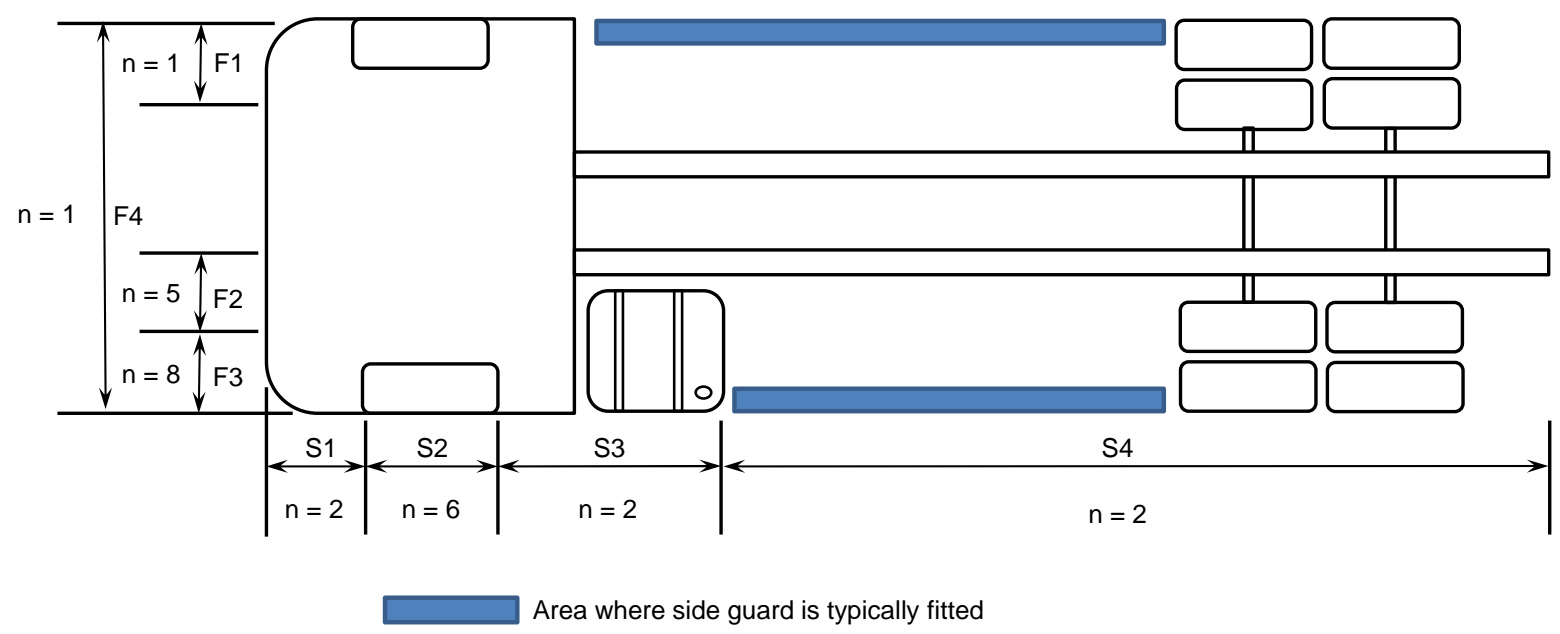

Figure 3: Initial contact points of pedal cyclist and truck (adapted from Talbot et al. 2014) 


\section{Relative Movement of Cyclists and Trucks}

Overtaking and undertaking behaviours of the pedal cyclists and truck drivers were examined in terms of their relative movement - that is whether the cyclist or truck was travelling faster in relation to the other - just before the crash (Error! Reference source not found.2). For example, if a truck was stationary at traffic lights and a pedal cyclist travelled down the nearside of the truck and stopped ahead of it, then this was counted as an undertake manoeuvre by the pedal cyclist.

Table 2: Relative movement of Pedal Cyclists and Trucks

\begin{tabular}{|l|c|}
\hline \multicolumn{1}{|c|}{ Relative movement } & $\begin{array}{c}\text { Number of } \\
\text { crashes }\end{array}$ \\
\hline Cyclist overtaking stationary truck & 2 \\
\hline Cyclist overtaking moving truck & 0 \\
\hline Cyclist undertaking stationary truck & 11 \\
\hline Cyclist undertaking moving truck (not turning) & 0 \\
\hline Cyclist undertaking moving truck which was turning right & 8 \\
\hline Cyclist undertaking moving truck which was turning left & 0 \\
\hline Both moving together (similar speed) & 0 \\
\hline Truck overtaking stationary cyclist & 3 \\
\hline Truck overtaking moving cyclist & 2 \\
\hline Other crash configuration & 1 \\
\hline
\end{tabular}

In addition, undertake manoeuvres by the pedal cyclist may have been as a result of a truck slowing down, e.g. on the approach to traffic lights rather than a deliberate change or speed or action by the cyclist. For all 11 crashes where the cyclist was undertaking a stationary truck, the crash occurred at a traffic light controlled junction, five of which had an ASL. Where the pedal cyclist undertook a moving truck that was turning left (eight crashes), the crash occurred at a light controlled junction in six instances, and three of these had an ASL.

\section{Contributory Factors}

The following lists the most frequently assigned contributory factors for the crashes involving a truck $\geq 3.5$ tonnes $(\mathrm{n}=27)$ for each system element - Infrastructure, Vehicle, Road User and Management. The contributory factors were identified by the case reviews as described in the Methodology section. These factors are not unrelated and have to be viewed within the road traffic system as a whole.

Infrastructure:

- The cyclist waiting in the Advanced Stop Line area in front of the truck could not be seen by truck due to lack of class VI mirror (5 crashes) 
- Cyclist travelling straight ahead sharing lane with truck turning left at junction (6 crashes)

- Road narrowing e.g. lane (s) reducing in width or another obstacle such as a pedestrian crossing protruding into the lane ( 6 crashes)

Vehicle:

- Problem with the ability of the truck driver to see cyclist - cab design (26 crashes)

o no direct vision (without mirror) to area to the nearside of the vehicle $(19 / 26)$

o no direct vision (without mirror) to the area in front of vehicle (7/26)

- Pedal cyclist run over by truck - injury causation (27 crashes)

Road User:

- Inappropriate position of cyclist e.g. riding/waiting to the nearside side of truck (15 crashes)

- Truck driver not allowing enough space between truck and cyclist e.g. when overtaking or following too closely (3 crashes)

Management:

- Crash occurred between 07:00 - 09:59 (morning peek commuting traffic period) (14 crashes)

o Crash occurred between 08:00 - 08:59 (10/14)

\section{DISCUSSION}

Twenty-seven crashes involving pedal cyclists and trucks were examined. The most common scenario involved the truck turning left whilst the cyclist travelled straight on and was either positioned just in front or to the nearside front of the truck (18 crashes). Another common scenario involved the cyclist running out of space while travelling on the nearside of a truck either due to road narrowing or the truck manoeuvre (nine crashes). The fatal and serious injuries were caused by the cyclist being run over by the truck in all 27 crashes and initial contact with the truck was clustered around the nearside front cab area $(n=21)$ - a finding similar to that of Niewoehner and Berg (2005). Nearly two thirds of crashes in the sample involved female pedal cyclists (17/27). In contrast, a much smaller proportion of females have been observed in the general London pedal cycle population where, according to Steinbach et al (2011) and TfL (2015), only a third of pedal cyclists are female and make only a third of the trips on bicycles compared to males. However due to the small sample size of this study, conclusions cannot be drawn about the significance of this.

A key issue identified in this research was that pedal cyclists were being run over when positioned in close proximity to the front or left side of the cab area. A possible explanation to this is that truck drivers were not aware that the cyclist was in such close proximity to their vehicle. The current design of cabs means that there are areas to the front and nearside of trucks which are blind spots for the driver, that is the driver has no direct sight of the cyclist when they are positioned in this area. The fitting of Class V and Class VI mirrors aimed to reduce these blind spots (EC directive 2003/97/EC). However, research by Cook et al (2011) identified that 
there is still a blind spot to the nearside cab area where cyclists could be positioned. In addition the presence of class V and VI mirrors did not prevent the fatal crashes occurring in the sample discussed here.

The relative positions of the cyclist and the truck are dynamic and therefore the amount of time that a cyclist is visible in a mirror is very short. That coupled with the length of time it takes a driver to complete a full set of mirror checks - this may be five seconds according to Cook et al (2011) - and the other observations the driver is required to make (pedestrians, traffic signals) especially when negotiating a junction, makes it very difficult for the truck driver to observe the cyclist. Although not quantifiable in this study, anecdotal evidence from the interview transcripts between drivers and the police suggest that some truck drivers consider the class $\mathrm{V}$ and VI mirrors to be primarily parking and manoeuvring mirrors and therefore may not use these mirrors to check for cyclists around their truck. This is supported by Schoon et al (2008) who found that drivers were not using their mirrors correctly.

Cyclist behaviour may also play a part. As observed in some of the crashes in this study, pedal cyclists sometimes undertake slower moving or stationary vehicles on the approach to signalised junctions, thus finding themselves in a position where it is difficult for them to be seen by truck drivers. In addition, cyclists may not be aware of truck blind spots and may misinterpret the behaviour of the truck, for example, a left turning truck may position themselves in a central or right hand road position in order to have enough space to make a turn leading the cyclist to believe that the truck was travelling straight on. The cyclist may inadvertently undertake if other vehicles brake - especially in the lead up to traffic signals. Cyclist infrastructure may also influence where cyclists travel. Cycle lanes are often adjacent to the kerb and ASL entry points are also frequently to the nearside. In this way the infrastructure may be encouraging the cyclist to choose a position that makes them less visible to truck drivers.

Another issue raised by the results of this study is that despite the fitting of side guards to 11 of the 24 trucks where the fitment of sideguards was known, all the cyclists were run over by at least one set of wheels of the truck. This was usually because the cyclists were going under the truck in an area other than that which the side guards were fitted (e.g. front corner of cab) or the cyclist was already on the ground as the trailer moved over them allowing them to go under the side guard. Caution should be taken however in the conclusions drawn from this as the sample of crashes by definition only show when the side guard did not prevent injury. If the side guard had prevented this e.g. by pushing the cyclist clear, then they would not be part of this sample.

The results reported here also suggest a number of possibilities for specific countermeasures. For example, redesigning truck cabs to afford the driver better direct sight of cyclists traveling in close proximity to the front and front nearside of the truck, e.g. through lowering the windscreen and windows, may increase the chances of truck drivers observing cyclists. Attempts could also be made to increase the awareness of pedal cyclists of the dangers of undertaking trucks, especially on the approach to junctions. Pedal cyclists should be advised to wait behind the truck or overtake and position themselves where they can be visible to the driver. This could be achieved through the use of campaigns and additions to the UK Highway Code. Alterations could also be made to ASLs which may help to change pedal cyclist behaviour and increase their visibility. For example, positioning the entry point to ASLs to between lanes rather than next to the kerb would encourage overtaking and creating a 'no wait zone' between the motorised vehicle stop line and the start of the ASL 'box' would 
position cyclists further forwards and again increase the chances of them being seen by truck drivers. However further research would be required to establish the feasibility and cost-benefit of these suggestions and whether they would create any disadvantages for the safety of pedal cyclists or other road users.

The sample is small and as such the results should not be considered to be fully generalizable, rather they are indicative of the factors associated with pedal cycle and truck crashes that result in severe or fatal injury (MAIS3+). As this study predominately examined fatal crashes, it as such only examined the failures in the system. For example the truck sample includes crashes where mirrors and side guards were not effective but it is not possible to judge how effective these are in general. Although the police files were a rich source of information it was difficult to assess aspects relating to the management of the road traffic system such as route choice, truck company policy or pedal cyclist experience and training as these were either unobtainable or not relevant to the police investigation.

Crashes involving pedal cycle and truck collisions are still an issue - particularly in London and where trucks are turning left and the pedal cyclist is travelling straight ahead. The detailed nature of the data from the indepth police investigations analysed on individual crash basis as described in the methods section, gives an insight into the specific types of conflicts and interactions that occur in urban truck involved pedal cycle crashes. The level of detail afforded by these methodologies gives a much greater level of insight than that which is available from national reported road casualty statistics (e.g. STATS19). Further incite was provided by the coding of injury type and severity enabling a more thorough understanding of the injuries sustained by cyclists beyond the police categories of 'slight', 'serious' and 'fatal' that are included in national statistics. Previous studies have shown that actual injury severity is not comparable to the police categorisations with many injuries reported as 'serious' but in reality were 'minor' whereas AIS coding provides a standardised approach and therefore a more accurate picture of the injuries pedal cyclists actually received (Morris et al 2003). It can therefore be concluded that the in depth methodologies, including case reviews, utilised here have potential to add to the body of knowledge on pedal cyclist accidents and therefore complement studies using national level data.

The sample of cyclist verses truck crashes discussed here provide many suggestions about what contributed to them and ideas about the areas to focus upon for generating countermeasures to them. Broad areas for consideration that have been indicated by the truck crashes discussed include:

- Cab design

- Cyclist awareness of trucks and behaviour

- Truck driver awareness of cyclists

- Ways of preventing cyclists going under trucks e.g. improved side guards

- Design of cycling facilities where cyclists share the road with trucks.

- Limiting the movement of trucks during peak travel times

The authors would like to acknowledge the detailed work in relation to the broad areas listed above that is ongoing on the European, national and local London level.

\section{ACKNOWLEDGMENTS}


Data included in this paper were originally collected as part of a larger body of work funded by Transport for London that examined Pedal Cycle crashes occurring in London between 2007 and 2011 (Talbot et. al. 2014). The authors would like to acknowledge the assistance of both Transport for London and the Metropolitan Police Service in providing access to the data used in this paper.

\section{REFERENCES}

Ackery, A,D. Bicyclist deaths and striking vehicles in the USA. Inj Prev. 2012;18(1): 22-26.

Association for the Advancement of Automotive Medicine Abbreviated Injury Scale 2005 - 2008 update. AAAM; 2008.

College of Policing. Investigating road deaths. 2014. Available at: https://www.app.college.police.uk/appcontent/road-policing-2/investigating-road-deaths/. Accessed April 01, 2015.

Cook, S., Summerskill, S., Marshall, R., Richardson, J., Lawton, C. ,Grant, R., Bayer, S., Lenard, J., Clemo, K. The development of improvements to drivers' direct and indirect vision from vehicles. Phase 2. Technical report for the Department for Transport; 2011

DaCoTa. Pan-European In-Depth Accident Investigation Online Manual. 2012 Available at: http://dacotainvestigation-manual.eu/. Accessed April 01, 2015.

Department for Transport. Reported Road Casualties Great Britain: 2013 Annual Report - Focus on pedal cyclists. 2013. Available at:

https:/www.gov.uk/government/uploads/system/uploads/attachment_data/file/358042/rrcgb2013-02.pdf. Accessed July 21, 2015.

Department for Transport. Reported Road Casualties in Great Britain - Main Results 2014. Statistical Release 25 June 2015. Available at:

https://www.gov.uk/government/uploads/system/uploads/attachment_data/file/438040/reported-road-casualtiesin-great-britain-main-results-2014-release.pdf . Accessed July 21, 2015.

2003/97/EG, Directive of the European Parliament and the Council of 10th November 2003 on the approximation of regulations of the Member States for the type approval of devices for the indirect view and for vehicles fitted with such devices, as well as to amend the Directive 70/156/ECC and to rescind Directive 71/127/EWG, Official Bulletin of the European Union 29.01.2004, L25/1-45.

Haddon W. The changing approach to the epidemiology, prevention, and amelioration of trauma: the transition to approaches etiologically rather than descriptively based. Am J Public Health. 1968;58:1431-8

Hennink, M., Hutter, I., Bailey, A. Qualitative Research Methods. London: Sage; 2011 
HM Government (2015) Working together to safeguard children - A guide to inter-agency working to safeguard and promote the welfare of children. Available at:

https://www.gov.uk/government/uploads/system/uploads/attachment_data/file/419595/Working_Together to_S afeguard_Children.pdf Accessed April 01, 2015.

Johannsen, H., Otte, D. Urban, M. Pre-Crash Analysis of accidents Involving Turning Trucks and Bicyclists. International Research Council on Biomechanics of Injury (IRCOBI) Conference, 9-11 Sept 2015, Lyon, France. Available at: www.ircobi.org/downloads/irc15/pdf files/87.pdf Accessed Jan 14, 2016.

Kaplan, S., Vavatsoulas, K., Giacomo Prato, C. Aggravating and mitigating factors associated with cyclist injury severity in Denmark. J Safety Res. 2014;50:75-82.

Keigan, M., Cuerden, R., Wheeler, A. Analysis of police collision files for pedal cyclist fatalities in London, 2001-2006. Published Project Report PPR438. Transport Research Laboratory; 2009

Morris, A.P., Mackay, M., Wodzin, E., Barnes, J. Some Injury Scaling Issues in UK Crash Research. Proceedings of the 2003 International Research Council on Biomechanics of Injury (IRCOBI) Conference, 24 26 September, 2003,Lisbon, Portugal, 283-291.

Niewoehner, W., Berg, A. Endangerment of Pedestrians and Bicyclists at Intersections by Right Turning Trucks. 19th International Technical Conference on the Enhanced Safety of Vehicles (ESV) -. June 6-9, 2005, Washington D.C, USA.

Office for National Statistics. Cycling to Work Release of 2011 Census Analysis. 2014. Available at: http://www.ons.gov.uk/ons/rel/census/2011-census-analysis/cycling-to-work/sty-cycling-to-work.html. Accessed July 21, 2015

Public Health Wales. Thematic review of deaths of teenagers aged 13 to 17 years in motor vehicles between 2006-2010. 2013. Available at

http://www.wales.nhs.uk/sitesplus/documents/888/cdr\%20thematic\%20review.pdf. Accessed April 01, 2015.

Pilkington, P., Bird, E., Gray, S., Towner, E., Weld, S., McKibben, M. Understanding the social context of fatal road traffic collisions among young people: a qualitative analysis of narrative text in coroners' records. BMC Public Health. 2014; 14:78.

Reason, J. Human error: models and management. BMJ, 2000;320:768-70

Reed, S., Morris, A. Glossary of Data Variables for Fatal and accident causation databases. Deliverable 5.5 of the European Commision supported SafetyNet project. 2008. Available at:

http://erso.swov.nl/safetynet/fixed/WP5/D5.5\%20Glossary\%20of $\% 20$ Data $\% 20$ variables $\% 20$ for $\% 20$ Fatal $\% 20$ an d $\% 20$ accident $\% 20$ causation $\% 20$ databases.pdf

Schoon, C. C., Doumen, M.J.A, de Brui, D. The circumstances of blind spot crashes and short- and long-term measures: a crash analysis over the years 1997-2007, traffic observations, and surveys among cyclists and lorry drivers. The Hague, SWOV report; 2008. 
Shappell, S. \& Wiegmann, D. The human factors analysis and classification system - HFACS. DOT/FAA/AM00/7, Office of Aviation Medicine, Federal Aviation Administration, Department of Transportation; 2000

Steinbach, R., Green, J., Datta, J., Edwards, P. Cycling and the city: A case study of how gendered, ethnic and class identities can shape healthy transport choices. Soc Sci Med. 2011;72(7):1123-1130.

Stone, M., Broughton, J. Getting off your bike: cycling accidents in Great Britain in 1990-1999. Accid Anal Prev. 2003;35:549-556

Talbot R, Reed S, Barnes J, Thomas P, Christie N. Pedal cyclist fatalities in London: analysis of police collision files (2007-2011). Loughborough University and University College London and on behalf of Transport for London; 2014. Available from: https://tfl.gov.uk/corporate/publications-and-reports/road-safety

Transport for London. The Mayor's vision for cycling in London. London: Greater London Authority. 2013. Available at: https://tfl.gov.uk/cdn/static/cms/documents/gla-mayors-cycle-vision-2013.pdf Accessed July 21, 2015

Transport for London. London Travel Demand Survey 2013/14. 2015. Available at: https://tfl.gov.uk/corporate/publications-and-reports/london-travel-demand-survey Accessed Sept 32015.

Wallén-Warner, H., Björklund, G., Johansson, E., Ljung Aust, M., Sandin, J., Manual for DREAM 3.0 - Driving Reliability and Error Analysis Method. Deliverable D5. 6 of the EC FP6 Project SafetyNet; 2008

Wiegmann, D.A. and Shappell, S.A. A Human Error Approach to Aviation Accident Analysis: The Human Factors Analysis and Classification System. Ashgate Publishing, Ltd. pp. 48-49. ISBN 0754618730; 2003 


\section{APPENDIX}

Table A1: Maximum AIS by body region for cyclists killed or seriously injured following a collision with a truck

\begin{tabular}{|c|c|c|c|c|c|}
\hline $\begin{array}{l}\text { ISS Body } \\
\text { Region }\end{array}$ & Head or Neck & Thorax & Abdomen & Extremities & Total \\
\hline \multicolumn{6}{|c|}{ Female - Fatal } \\
\hline MAIS 3 & 1 & 0 & 0 & 1 & 2 \\
\hline MAIS 4 & 1 & 3 & 1 & 1 & 6 \\
\hline MAIS 5 & 0 & 1 & 1 & 1 & 3 \\
\hline MAIS 6 & 0 & 2 & 0 & 0 & 2 \\
\hline \multicolumn{6}{|c|}{ Female - Serious } \\
\hline MAIS 3 & 0 & 0 & 0 & 3 & 3 \\
\hline \multicolumn{6}{|c|}{ Male - Fatal } \\
\hline MAIS 3 & 0 & 1 & 0 & 0 & 1 \\
\hline MAIS 4 & 2 & 0 & 0 & 0 & 2 \\
\hline MAIS 5 & 1 & 2 & 0 & 0 & 3 \\
\hline MAIS 6 & 2 & 1 & 0 & 0 & 3 \\
\hline Total & 7 & 10 & 2 & 6 & 25 \\
\hline
\end{tabular}

Table A2: Crash Scenario categories (bold text) and sub-categories (italics) and associated number of crashes

\begin{tabular}{|l|l|l|}
\hline $\begin{array}{l}\text { Category/ sub- } \\
\text { category }\end{array}$ & Crash Scenario Description & $\begin{array}{l}\text { No. of } \\
\text { Crashes }\end{array}$ \\
\hline $\mathbf{1}$ & Truck turning left & $\mathbf{1 8}$ \\
\hline $1 a$ & Dynamic & 7 \\
\hline $1 b$ & Setting off & 4 \\
\hline $1 c$ & Left turn only with restricted (cycle/bus) 'straight on' lane & 2 \\
\hline $1 d$ & $\begin{array}{l}\text { Cyclist used pavement to undertake other vehicles and re-entered } \\
\text { carriageway to left of truck }\end{array}$ & 3 \\
\hline $1 e$ & Truck failed to give way to cyclist & 2 \\
\hline $\mathbf{2}$ & Travelling in same direction & $\mathbf{9}$ \\
\hline $2 a$ & Running out of space & 7 \\
\hline $2 b$ & Cyclist entering space ahead of stationary truck & 2 \\
\hline
\end{tabular}




\section{Database Variables and Values - Tables A3-A10}

The following tables are the variables and values that were collected about the truck and cyclists crashes included in this paper. It should be noted that information was not available for every variable for every crash and not all these variables were included in the analysis presented here. The full list is included here for completeness. Variables are divided into five categories: 'Accident', 'Infrastructure', 'Vehicle', 'Road User' and 'Injuries'. Two tables have been created for each category the first listing the variables and their type and the second lists the values for variables with 'Multiple Options' as the variable type.

Table A3: Accident variables and type

\begin{tabular}{|l|l|}
\hline Accident Variable Name & Variable type \\
\hline Case Number & Number \\
\hline Day & Number \\
\hline Month & Number \\
\hline Year & Number \\
\hline Day of Week & Multiple Options \\
\hline Hour & Number \\
\hline Minute & Number \\
\hline Hit and Run & Yes/No \\
\hline Type of collision & Multiple Options \\
\hline Accident Description & Free Text \\
\hline Location & Free Text \\
\hline General comments & Free Text \\
\hline
\end{tabular}

Table A4: Values for multiple option accident variables

\begin{tabular}{|l|l|}
\hline Accident Variable Name & Multiple Option Values \\
\hline Day of Week & Monday \\
& Tuesday \\
Wednesday & Thursday \\
Friday & Saturday \\
Sunday & \\
\hline Type of collision & Travelling alongside \\
& Vehicle turns right across P/C path \\
& Vehicle turns left across P/C path \\
& Hit/ swerve to avoid open door \\
& Vehicle disobeys control, turns right into P/C path \\
& Vehicle fails to give way \& collides with P/C \\
& Vehicle runs into rear of P/C \\
& P/C rides of footway into path of vehicle \\
& Vehicle disobeys control, turns left into P/C path \\
& Head on collision \\
& P/C runs into rear of vehicle \\
& Loss of control only \\
& P/C fails to give way \& collides with vehicle \\
& Vehicle changes lanes to left across P/C path \\
& Both turning left
\end{tabular}


Hit parked vehicle

vehicle pulls out into $\mathrm{P} / \mathrm{C}$ path

$\mathrm{P} / \mathrm{C}$ disobeys control, turns right into vehicle path

$\mathrm{P} / \mathrm{C}$ rides across crossing into vehicle path

$\mathrm{P} / \mathrm{C}$ turns right across vehicle path

Loss of control hit vehicle

$\mathrm{P} / \mathrm{C}$ disobeys control, turns left into vehicle path

Vehicle changes lanes to right across $\mathrm{P} / \mathrm{C}$ path

$\mathrm{P} / \mathrm{C}$ strikes pedestrian not within $50 \mathrm{~m}$ of crossing

$\mathrm{P} / \mathrm{C}$ overtakes into path of right turning vehicle

Vehicle U-turn into path of P/C

$\mathrm{P} / \mathrm{C}$ changes lane to right across vehicle path

$\mathrm{P} / \mathrm{C}$ in collision with pedestrian on crossing

vehicle reverses into $\mathrm{P} / \mathrm{C}$

$\mathrm{P} / \mathrm{C}$ changes lane to left across vehicle path

$\mathrm{P} / \mathrm{C}$ and vehicle turning right

Not known

Table A5: Infrastructure variables and type

\begin{tabular}{|l|l|}
\hline Infrastructure Variable Name & Variable type \\
\hline Junction & Multiple options \\
\hline Junction control & Multiple options \\
\hline Road type & Multiple options \\
\hline Carriageway type & Multiple options \\
\hline Traffic conditions & Multiple options \\
\hline Posted speed limit & Number \\
\hline Average traffic speed & Number \\
\hline Weather conditions & Multiple options \\
\hline Other weather & Multiple options \\
\hline Light conditions & Multiple options \\
\hline Road conditions & Multiple options \\
\hline Traffic calming & Number \\
\hline Traffic calming comment & Free text \\
\hline Land use & Multiple options \\
\hline Vertical alignment & Multiple options \\
\hline Horizontal alignment & Multiple options \\
\hline Element 1 & Multiple options \\
\hline Element 2 & Multiple options \\
\hline Element 3 & Multiple options \\
\hline Element 4 & Multiple options \\
\hline Element 1 lane marking & Yes/No/Not known \\
\hline Element 2 lane marking & Yes/No/Not known \\
\hline Element 3 lane marking & Yes/No/Not known \\
\hline Element 4 lane marking & Yes/No/Not known \\
\hline Where was vehicle & Multiple options \\
\hline Where in lane - cyclist & Multiple options \\
\hline Where in lane - vehicle & Multiple options \\
\hline Measurement if known & Number \\
\hline Lane comment & Free text \\
\hline Lane width & Number \\
\hline Road narrows & Free text \\
\hline & \\
\hline
\end{tabular}




\begin{tabular}{|l|l|} 
Parked vehicles & Yes/No/Not known \\
\hline Parked vehicle comment & Free text \\
\hline Passing manoeuvre & Free text \\
\hline Guardrails & Multiple options \\
\hline Guardrails Comments & Free text \\
\hline Surface condition & Multiple options \\
\hline Advanced Stop Line present & Yes/No/Not known \\
\hline Visibility / sight lines comments & Free text \\
\hline Roadway Comments & Free text \\
\hline
\end{tabular}

Table A6: Values for multiple option infrastructure variables

\begin{tabular}{|c|c|}
\hline Infrastructure Variable Name & Multiple Option Values \\
\hline Junction & $\begin{array}{l}\text { Not at or within } 20 \text { metres of junction } \\
\text { Roundabout } \\
\text { Mini roundabout } \\
\text { T junction } \\
\text { Staggered junction } \\
\text { Slip road } \\
\text { Crossroads } \\
\text { Multiple junction } \\
\text { Using private drive or entrance } \\
\text { Other junction type } \\
\text { Not known }\end{array}$ \\
\hline Junction control & $\begin{array}{l}\text { None } \\
\text { Give way } \\
\text { Stop } \\
\text { Light controlled } \\
\text { Light/ sign controlled roadworks } \\
\text { Authorised person }\end{array}$ \\
\hline Road type & $\begin{array}{l}\text { A } \\
\text { B } \\
\text { C } \\
\text { Unclassified }\end{array}$ \\
\hline Carriageway type & $\begin{array}{l}\text { At junction } \\
\text { One way } \\
\text { Two way } \\
\text { Other } \\
\text { Not known }\end{array}$ \\
\hline Traffic conditions & $\begin{array}{l}\text { Heavy (peak) traffic flow } \\
\text { Moderate (off peak daytime) traffic flow } \\
\text { Light (off peak night) traffic flow } \\
\text { Other } \\
\text { Not Known }\end{array}$ \\
\hline Weather conditions & $\begin{array}{l}\text { Fine } \\
\text { Cloudy } \\
\text { Rain }\end{array}$ \\
\hline
\end{tabular}




\begin{tabular}{|c|c|}
\hline & $\begin{array}{l}\text { Snow } \\
\text { Fog } \\
\text { Other } \\
\text { Not known }\end{array}$ \\
\hline Road conditions & $\begin{array}{l}\text { Dry } \\
\text { Wet } \\
\text { Ice } \\
\text { Snow } \\
\text { Other } \\
\text { Not known }\end{array}$ \\
\hline Light conditions & $\begin{array}{l}\text { Daylight } \\
\text { Partial light } \\
\text { Darkness } \\
\text { Darknesswith artificial light } \\
\text { Other }\end{array}$ \\
\hline Other weather & $\begin{array}{l}\text { Glare } \\
\text { High winds } \\
\text { Both } \\
\text { Other }\end{array}$ \\
\hline Land use & $\begin{array}{l}\text { Low cost residential } \\
\text { Medium cost residential } \\
\text { High cost residential } \\
\text { Centre business district } \\
\text { Industrial/manufacturing } \\
\text { Outlying business district } \\
\text { Commuter zone }\end{array}$ \\
\hline Guardrails & $\begin{array}{l}\text { No } \\
\text { Yes - involved } \\
\text { Yes - not involved } \\
\text { Not known }\end{array}$ \\
\hline Vertical alignment & $\begin{array}{l}\text { Flat } \\
\text { Uphill } \\
\text { Downhill } \\
\text { Not known }\end{array}$ \\
\hline Horizontal alignment & $\begin{array}{l}\text { Straight road } \\
\text { Road bends to Right } \\
\text { Road bends to Left } \\
\text { Junction turns to Right - gentle } \\
\text { Junction turns to Left - gentle } \\
\text { Junction turns to Right - sharp } \\
\text { Junction turns to Left - sharp } \\
\text { Other } \\
\text { Not known }\end{array}$ \\
\hline $\begin{array}{l}\text { Element } 1 \\
\text { Element } 2 \\
\text { Element } 3\end{array}$ & $\begin{array}{l}\text { Footway } \\
\text { Pedestrianised area } \\
\text { Diverted footway }\end{array}$ \\
\hline
\end{tabular}




\begin{tabular}{|c|c|}
\hline Element 4 & $\begin{array}{l}\text { Cycle track } \\
\text { Shared cycle track } \\
\text { Cycle superhighway } \\
\text { Restricted cycle lane } \\
\text { Unrestricted cycle lane } \\
\text { Advanced stop line } \\
\text { Unrestricted lane } \\
\text { Roadworks/construction } \\
\text { Bus lane } \\
\text { Bus and taxi lane } \\
\text { Bus, taxi and cycle lane } \\
\text { Other } \\
\text { Not known }\end{array}$ \\
\hline Where was cyclist/vehicle & $\begin{array}{l}\text { Element } 1 \\
\text { Element } 2 \\
\text { Element } 3 \\
\text { Element } 4 \\
\text { Opposing lane } \\
\text { Not known }\end{array}$ \\
\hline Where in lane - cyclist & $\begin{array}{l}\text { Nearside } \\
1 / 3 \\
\text { Centre } \\
3 / 3 \\
\text { Offside } \\
\text { Not applicable } \\
\text { Other } \\
\text { Not known }\end{array}$ \\
\hline Passing & $\begin{array}{l}\text { Not passing } \\
\text { Vehicle overtaking } \\
\text { Vehicle undertaking } \\
\text { Cyclist overtaking } \\
\text { Cyclist undertaking } \\
\text { Other } \\
\text { Not Known }\end{array}$ \\
\hline Where in lane - vehicle/cyclist & $\begin{array}{l}\text { Centre } \\
\text { Offside } \\
\text { Nearside } \\
\text { Straddling } \\
\text { Other } \\
\text { Not Known }\end{array}$ \\
\hline Surface condition & $\begin{array}{l}\text { None } \\
\text { Pot hole } \\
\text { Raised iron work } \\
\text { Temporary surface } \\
\text { Mud } \\
\text { Leaves } \\
\text { Oil } \\
\text { Diesel } \\
\text { Gravel }\end{array}$ \\
\hline
\end{tabular}


Table A7: Vehicle variables and type

\begin{tabular}{|c|c|}
\hline Vehicle Variable Name & Variable type \\
\hline Vehicle Number & Number \\
\hline Number of Occupants & Number \\
\hline Vehicle Class & Multiple options \\
\hline Vehicle Type & Multiple options \\
\hline Vehicle Body & Multiple options \\
\hline Vehicle type comment & Free text \\
\hline Vehicle Make & Free text \\
\hline Vehicle Model & Free text \\
\hline Registration age identifier & Number/Letter \\
\hline Year Of Manufacture & Number \\
\hline Number of wheel positions & Number \\
\hline Number of driven wheels & Number \\
\hline Number of steered axles & Number \\
\hline Drive Of Vehicle & Multiple options \\
\hline Was vehicle towing & Yes/No/Not known \\
\hline Type of trailer & String \\
\hline Side guards fitted & Multiple options \\
\hline Wheel base length & Multiple options \\
\hline Vehicle length & Number \\
\hline Vehicle width & Number \\
\hline Vehicle carrying load & Yes/No/Not known \\
\hline Load comment & Free text \\
\hline Vehicle status & Free text \\
\hline Vehicle defects present & Yes/No/Not known \\
\hline Vehicle defects & Free text \\
\hline vehicle modifications & Free text \\
\hline General condition of vehicle & Free text \\
\hline Relevant E-safety fitted & Free text \\
\hline Mirror Class II O/S fitted & Yes/No/Not known \\
\hline Mirror Class II N/S fitted & Yes/No/Not known \\
\hline Mirror Class IV O/S fitted & Yes/No/Not known \\
\hline Mirror Class IV N/S fitted & Yes/No/Not known \\
\hline Mirror Class $\mathrm{V}$ O/S fitted & Yes/No/Not known \\
\hline Mirror Class VI fitted & Yes/No/Not known \\
\hline Mirror Class V N/S fitted & Yes/No/Not known \\
\hline Damage to mirrors & Yes/No/Not known \\
\hline Description of mirror damage & Free text \\
\hline Company Vehicle & Yes/No/Not known \\
\hline Type of company & Free text \\
\hline Vehicle specific speed limit & Number \\
\hline Pre impact speed highest estimate & Number \\
\hline Pre impact speed lowest estimate & Number \\
\hline Impact speed highest estimate & Number \\
\hline Impact speed lowest estimate & Number \\
\hline Bicycle lights fitted & Multiple options \\
\hline
\end{tabular}




\begin{tabular}{|l|l|} 
Vehicle lighting in use & Yes/No/Not known \\
\hline lighting comments & Free text \\
\hline Driver manoeuvre prior to crash & Free text \\
\hline Crash Avoidance Manoeuvre & Multiple options \\
\hline Avoidance manoeuvre comment & Free text \\
\hline Bicycle/Vehicle interaction & Multiple options \\
\hline Interaction comment & Free text \\
\hline Collison orientation & Multiple options \\
\hline $\begin{array}{l}\text { Collision with objects other than } \\
\text { vehicles }\end{array}$ & Yes/No/Not known \\
\hline Description of objects hit/order & Free text \\
\hline Events description & Free text \\
\hline
\end{tabular}

Table A8: Values for multiple option vehicle variables

\begin{tabular}{|l|l|}
\hline Vehicle Variable Name & Multiple Option Values \\
\hline Vehicle class & Car/MPV/CDV \\
& Van \\
Bus/Minibus \\
Truck 3.5t \\
Truck 7.5t \\
Truck - HGV \\
Agricultural Vehicle \\
Motorcycle Moped \\
Bicycle \\
Train/Tram \\
Pedestrian \\
Other \\
Not known \\
\hline Tractor unit \\
Rigid unit \\
Articulated \\
Tractor \\
Agricultural machine \\
Ambulance \\
Fire engine \\
Recovery vehicle \\
Military vehicle \\
Horsebox \\
Construction machinery \\
Mechanical digger \\
Dumper \\
Forklift \\
Gully cleaner \\
Crane \\
Hydraulic platform \\
Milk float \\
Refuse lorry \\
Train \\
Other \\
Car/CDV \\
\hline
\end{tabular}




\begin{tabular}{|c|c|}
\hline & $\begin{array}{l}\text { Pedal cycle } \\
\text { Motorcycle/Moped } \\
\text { LCV } \\
\text { Bus } \\
\text { Coach } \\
\text { Purpose built Minibus } \\
\text { Van derived minibus }\end{array}$ \\
\hline Vehicle body & $\begin{array}{l}\text { Tractor unit only } \\
\text { Box } \\
\text { Car transporter } \\
\text { Container } \\
\text { Curtain sided } \\
\text { Flat or drop side } \\
\text { Livestock carrier } \\
\text { Skip carrier } \\
\text { Tanker } \\
\text { Panel } \\
\text { Tipper } \\
\text { Hatch } \\
\text { Estate } \\
\text { Saloon } \\
\text { CDV } \\
\text { Off-road } \\
\text { Sports } \\
\text { Single deck } \\
\text { Double deck } \\
\text { Bendy bus } \\
\text { Road bike } \\
\text { Mountain bike } \\
\text { Commuter/hybrid bike } \\
\text { Shopper } \\
\text { Folding } \\
\text { Recumbent } \\
\text { Hire } \\
\text { Other } \\
\text { Not known }\end{array}$ \\
\hline Wheelbase & $\begin{array}{l}\text { Short wheelbase } \\
\text { Long wheelbase } \\
\text { Not known }\end{array}$ \\
\hline Towing & $\begin{array}{l}\text { No } \\
\text { Yes } \\
\text { Not Known }\end{array}$ \\
\hline Drive of vehicle & $\begin{array}{l}\text { Right-hand-drive } \\
\text { Left-hand-drive } \\
\text { Other } \\
\text { Not applicable } \\
\text { Not Known }\end{array}$ \\
\hline Side guards & $\begin{array}{l}\text { None } \\
\text { Single bar }\end{array}$ \\
\hline
\end{tabular}




\begin{tabular}{|c|c|}
\hline & $\begin{array}{l}\text { Twin bar } \\
\text { Triple bar } \\
\text { Solid skirt } \\
\text { Other configuration } \\
\text { Not known }\end{array}$ \\
\hline Cycle lighting & $\begin{array}{l}\text { No } \\
\text { Yes NFS } \\
\text { Front only } \\
\text { Rear only } \\
\text { Front and rear } \\
\text { Multiple } \\
\text { Other } \\
\text { Not Known }\end{array}$ \\
\hline Crash avoidance manoeuvre & $\begin{array}{l}\text { None } \\
\text { Yes NFS } \\
\text { Braking (skid marks evident) } \\
\text { Braking (no skid marks evident) } \\
\text { Steering (evidence or stated) } \\
\text { Steering and braking (evidence or stated) } \\
\text { Other manoeuvre } \\
\text { Unknown }\end{array}$ \\
\hline Cycle/vehicle interaction & $\begin{array}{l}\text { None } \\
\text { Glancing Impact } \\
\text { Scooped up and came off vehicle } \\
\text { Thrown to nearside } \\
\text { Thrown to offside } \\
\text { Moved sideways across vehicle to nearside } \\
\text { Moved sideways across vehicle to offside } \\
\text { Thrown over vehicle } \\
\text { Thrown straight forwards } \\
\text { Thrown to side pavement } \\
\text { Thrown into traffic lane } \\
\text { Hit again by same vehicle } \\
\text { Hit by another vehicle } \\
\text { Dragged by vehicle } \\
\text { Went under vehicle } \\
\text { Other } \\
\text { Not Known }\end{array}$ \\
\hline Collision Orientation & $\begin{array}{l}\text { Front to Front } \\
\text { Front to Rear } \\
\text { Rear to Front } \\
\text { Side to Front (90 degrees) } \\
\text { Front to Side (90 degrees) } \\
\text { Side to Front (angle not specified) } \\
\text { Front to Side (angle not specified) } \\
\text { Sideswipe (same direction) } \\
\text { Sideswipe (opposite direction) } \\
\text { Other } \\
\text { Not Known }\end{array}$ \\
\hline
\end{tabular}


Table A9: Road user variables and type

\begin{tabular}{|l|l|}
\hline Road User Variable Name & Variable type \\
\hline Road User Type & Multiple Options \\
\hline Age & Number \\
\hline Gender & Multiple Options \\
\hline Ethnicity & Multiple Options \\
\hline Nationality & Multiple Options \\
\hline Country of residence & Multiple Options \\
\hline Area of residence & Free text \\
\hline Occupation & Free text \\
\hline Cycling Experience & Free text \\
\hline Driving Experience & Free text \\
\hline Licence status & Free text \\
\hline Driving convictions and history & Free text \\
\hline Further training & Free text \\
\hline Familiar with roads/route & Yes/No/Not known \\
\hline Journey purpose & Multiple Options \\
\hline journey purpose description & Free text \\
\hline Origin of journey & Free text \\
\hline Destination of journey & Free text \\
\hline Duration of Journey & Number \\
\hline type of route & Free text \\
\hline Illegal substances & Yes/No/Not known \\
\hline Alcohol & Yes/No/Not known \\
\hline Medication & Yes/No/Not known \\
\hline Disability & Yes/No/Not known \\
\hline Type of impairment and level & Free text \\
\hline Relevant personal circumstances. & Free text \\
\hline Seat belt worn & Yes/No/Not known \\
\hline Airbag deployed & Yes/No/Not known \\
\hline Airbag type/position & Free text \\
\hline Motorcycle helmet worn & Yes/No/Not known \\
\hline High vis material worn & Yes/No/Not known \\
\hline Description of high vis & Free text \\
\hline Clothing description & Free text \\
\hline Bicycle helmet worn & Yes/No/Not known \\
\hline Bicycle helmet type & Free text \\
\hline communication with other road \\
user & Free text \\
\hline Use of technology & Multiple Options \\
\hline Use of technology description & Free text \\
\hline Distraction involved & Multiple Options \\
\hline Describe Distraction & Free text \\
\hline Number of cyclists travelling \\
together & Number \\
\hline Passenger 1-3 position & \\
\hline Passenger 1-3 gender & Multiple Options \\
\hline Passenger 1-3 age & Massenger comments \\
\hline
\end{tabular}


Table A10: Values for multiple option road user variables

\begin{tabular}{|c|c|}
\hline Road User Variable Name & Multiple Option Values \\
\hline Road User Type & $\begin{array}{l}\text { Cyclist } \\
\text { Driver } \\
\text { Pedestrian }\end{array}$ \\
\hline $\begin{array}{l}\text { Gender } \\
\text { Passenger gender }\end{array}$ & $\begin{array}{l}\text { Male } \\
\text { Female } \\
\text { Not Known }\end{array}$ \\
\hline Ethnicity & $\begin{array}{l}\text { White British } \\
\text { White Irish } \\
\text { White (other) } \\
\text { Black Caribbean } \\
\text { Black African } \\
\text { Black (others) } \\
\text { Indian } \\
\text { Pakistani } \\
\text { Bangladeshi } \\
\text { Chinese } \\
\text { Other Asian (non-Chinese) } \\
\text { Mixed } \\
\text { Other } \\
\text { Not Known }\end{array}$ \\
\hline $\begin{array}{l}\text { Nationality } \\
\text { Country of residence }\end{array}$ & $\begin{array}{l}\text { [Full country list] } \\
\text { [Full country list] }\end{array}$ \\
\hline Journey purpose & $\begin{array}{l}\text { Private } \\
\text { Commute } \\
\text { To/from School } \\
\text { Work } \\
\text { Freight } \\
\text { Other } \\
\text { Not Known }\end{array}$ \\
\hline Use of technology & $\begin{array}{l}\text { None stated } \\
\text { Mobile - call } \\
\text { Mobile - text } \\
\text { Hands free } \\
\text { Headphones } \\
\text { Sat Nav } \\
\text { Radio } \\
\text { Other }\end{array}$ \\
\hline Distraction involved & $\begin{array}{l}\text { Yes } \\
\text { Possible }\end{array}$ \\
\hline Passenger 1-3 position & $\begin{array}{l}\text { Front } \\
\text { Rear } \\
\text { Other } \\
\text { Not Known }\end{array}$ \\
\hline
\end{tabular}


Table A11: Injury variables and type

\begin{tabular}{|l|l|}
\hline Injury Variable Name & Variable type \\
\hline Police Injury severity & Multiple Options \\
\hline Taken To Hospital & Yes/No/Not known \\
\hline Name of hospital taken to & Free text \\
\hline Hospital inpatient Duration & Number \\
\hline Died At Scene & Yes/No/Not known \\
\hline Number of days until death & Number \\
\hline Hospital treatment & Free text \\
\hline $\begin{array}{l}\text { Immediate first aid at } \\
\text { scene }\end{array}$ & Free text \\
\hline Height & Number \\
\hline Weight & Number \\
\hline Death Date & Date \\
\hline Data Source & Free Text \\
\hline Recorded Cause of Death & Free Text \\
\hline Toxicology & Free Text \\
\hline Injury Description & Free Text \\
\hline AlS code & Number \\
\hline Comments about injuries & Free text \\
\hline
\end{tabular}

Table A12: Values for multiple option Injury variables

\begin{tabular}{|l|l|}
\hline Injury Variable Name & Multiple Option Values \\
\hline Police Injury severity & Fatal \\
& Serious \\
& Slight \\
& Non injury \\
& Not Known \\
\hline
\end{tabular}

